\title{
Expressões metafóricas cotidianas
}

\author{
metaphorical everyday expressions
}

\author{
Sandra Bernardo \\ Naira de Almeida Velozo \\ Caroline Martins
}

Universidade do Estado do Rio de Janeiro - UERJ - Rio de Janeiro - Rio de Janeiro - Brasil

\begin{abstract}
Resumo: Com base na teoria da metáfora conceptual (LAKOFF (2002[1980], KÖVECSES, 2010b), são analisadas expressões metafóricas ou potencialmente metafóricas encontradas no Banco de Dados Interacionais (RONCARATI, 1996), volume que reúne transcrições de conversas gravadas entre novembro de 1989 e janeiro de 1991, totalizando cerca de 270 minutos. Com duração entre 5 e 30 minutos, as 13 conversas que compõem o volume foram segmentadas em 9927 unidades entonacionais (CHAFE, 1988; Du Bois et alii, 1992). Entre essas unidades, foram encontradas 82 expressões metafóricas que revelam a subjacência de domínios fonte e alvo amplamente apontados na literatura: PESSOA, EMOÇÃO, OBJETO, CORPO HUMANO, ECONOMIA e ANIMAL. Este estudo corrobora assunções acerca da teoria da metáfora conceptual, em suas manifestações linguísticas originais (ou não), no que tange às especificidades dos seus contextos de conceptualização em discursos reais.
\end{abstract}

Palavras-chave: Conversa informal. Metáfora conceptual. Metonímia conceptual. Domínios alvo e fonte.

\begin{abstract}
Based on conceptual metaphor theory (LAKOFF, (2002 [1980]; KÖVECSES, $2010 \mathrm{~b})$, metaphorical or potentially metaphorical expressions found in the Banco de Dados Interacionais (RONCARATI, 1996) a volume that contains transcripts of conversations recorded between November 1989 and January 1991 totaling about 270 minutes, are analyzed. Lasting between 5 and 30 minutes, the 13 conversations that make up this volume were segmented in 9927 intonational units (CHAFE, 1988; Du Bois et alii, 1992). Of these units, 82 metaphorical expressions were found that reveal source and target domains widely reported in the literature: PERSON, EMOTION, OBJECT, HUMAN BODY, ECONOMY and ANIMAL. This study confirms assumptions about the theory of conceptual metaphor, in their original linguistic manifestations (or not), with respect to the specifics of their conceptualization contexts in real talk.
\end{abstract}

Keywords: Informal talk. Conceptual metaphor. Conceptual metonymy. Target and source domains. 


\section{Introdução}

Sob a abordagem das teorias da metáfora e da metonímia conceptuais, analisam-se expressões metafóricas em conversas informais do Banco de Dados Interacionais (RONCARATI, 1996), publicação composta por treze interações com duração entre 5 e 30 minutos, totalizando cerca de 270 minutos de gravação. As conversas, gravadas entre novembro de 1989 e janeiro de 1991, foram segmentadas em 9927 unidades entonacionais, conforme o sistema de transcrição de Chafe (1988), com adaptações de Du Bois et alii (1992). Os resultados expostos, neste texto, correspondem a uma etapa de pesquisa, em andamento, que buscou investigar o tipo de conceptualização metafórica presente em conversa informal, no que tange às formas linguísticas usadas como gatilho/veículo para a postulação de uma metáfora conceptual e aos domínios fonte e alvo, subjacentes à conceptualização, construída conjuntamente pelos participantes da interação.

Apesar da naturalidade e da aparente facilidade com que pessoas conversam, o estudo desse tipo de interação sempre revela desafios, devido aos seus múltiplos aspectos: raciocínios, inferências, posições negociadas, deslocamentos de tópicos, mudanças de perspectivas, gerenciamento de informações e de interação, entre outras variáveis sociais e cognitivas, acionadas simultaneamente. 0 desafio começa com as dificuldades de coleta de amostras de fala informais (e espontâneas), sem qualquer tipo de monitoramento, em presença de um gravador ou de uma filmadora.

Concernente ao estudo de metáforas conceptuais, esse desafio aumenta, visto que, embora a metáfora seja reconhecida no âmbito da Linguística Cognitiva como um processo de construção de sentidos, não se pode controlar o momento em que possa surgir durante uma conversa com planejamento online e gerenciamento de tópicos discursivos livremente negociados pelos participantes da interação, ou seja, sem qualquer estratégia motivadora de assuntos a serem abordados ou algum tipo de controle da pessoa responsável pela gravação. Esses aspectos se revelam no número de expressões metafóricas (ou potencialmente metafóricas) encontradas em relação ao total de unidades entonacionais: 82 em 9927.

Algumas dessas ocorrências são tão convencionais que configuram metáforas primárias ou esquemas de conhecimentos basilares, relacionados ao caráter corporificado da construção de sentidos conjunta dos interlocutores. Assim, alguns casos não foram relacionados a metáforas conceptuais, mas a uma conceptualização potencialmente metafórica. Contudo, em razão do caráter informal e do planejamento local, o número de ocorrências não causou estranhamento. Além disso, foi possível comprovar as observações de estudos sobre metáforas e metonímias, bem como perceber, nestes dados, alguns aspectos relevantes sobre a ativação de pensamento metafórico.

Neste texto, trata-se de expressões metafóricas cujos domínios alvo e/ou fonte conceptualizam mais de dez construções. Antes de passar à análise, serão apresentados os fundamentos teóricos deste estudo.

\section{Fundamentação teórica}

Concebidas na Linguística Cognitiva como uma forma de raciocínio, as metáforas permitem a conceptualização de um domínio em termos do outro. Segundo Lakoff e Johnson (2002[1980]), os processos do pensamento são em grande parte metafóricos: "a essência da metáfora é compreender e experienciar uma coisa em termos da outra" (LAKOFF; JOHNSON, 2002: 43). A compreensão de discussão em termos de guerra, presente em "seus argumentos são indefensáveis"; "ele atacou todos os pontos fracos da minha argumentação" e "suas críticas foram direto ao alvo", evidenciada pelas expressões linguísticas grifadas, ilustram, por exemplo, a metáfora conceptual DISCUSSÃO É GUERRA. Essa metáfora surge da integração entre dois domínios distintos: o domínio fonte GUERRA com base no qual o domínio alvo DISCUSSÃo é experienciado.

Essa visão experiencialista de metáfora está 
alinhada com a hipótese da corporificação dos sentidos, uma assunção basilar da LC, segundo a qual a natureza orgânica influencia a experiência de mundo refletida quando se usa a língua. Nessa abordagem, o significado é (i) perpectivizado; (ii) dinâmico e flexível; (iii) enciclopédico e não autônomo; (iv) baseado no uso e na experiência.

Semelhantes às metáforas, na Linguística Cognitiva, metonímias também apresentam uma natureza conceitual, porque consistem em um processo cognitivo em que uma entidade conceptual, um veículo, fornece acesso mental à outra entidade conceptual, o alvo, dentro de um mesmo domínio, ou modelo cognitivo idealizado (KÖVECSES, 2010a: 173). A relação entre metáforas e metonímias conceptuais pode revelar metáforas motivadas por metonímias e metonímias constituídas por metáforas de modo que ambas podem vistas como processos escalares.

Vários estudos foram desenvolvidos desde 0 trabalho fundador de Lakoff e Johnson (2002 [1980]) no sentido de verificar a universalidade e a variação nas conceptualizações metafóricas, bem como a criatividade e a convencionalidade desse processo. Além disso, investigações sobre o contexto de uso da metáfora e sua relação com questões culturais tomaram corpo, a fim de testar a existência das metáforas, postuladas introspectivamente por Lakoff e Johnson (2002 [1980]), e o escopo da própria teoria da metáfora conceptual.

Kövecses (2010b), além de relacionar metáforas criativas ao mecanismo cognitivo da mesclagem, defende que a conceptualização metafórica expressa cotidianamente está sujeita a dois tipos de pressão por coerência: a pressão das experiências corporificadas e a pressão do contexto de ocorrência da conceptualização. A discussão em torno do corpo e do contexto de uso da metáfora leva à questão da universalidade e da variação na conceptualização metafórica.

Metáforas primárias, ligadas a esquemas imagéticos de QUANTIDADE e VERTICALIDADE, oriundos da relação entre corpo e ambiente, como BOM É PARA CIMA, apresentam um potencial para universalidade, ao passo que metáforas sensíveis ao contexto de uso evidenciam a variação metafórica. Um exemplo desse caso é a versão chinesa para a metáfora RAIVA É FLUIDO QUENTE NUM CONTÊINER, baseada na noção culturalmente significativa de qi, uma energia conceptualizada como um gás (ou fluido) que corre pelo corpo e pode crescer, gerando um excesso, quando se sente raiva. Assim, encontra-se em chinês a metáfora RAIVA É EXCESSO DE QI NO CORAÇÃO - the anger qi in one's heart (KÖVECSES, 2010a: 200).

Kövecses (2010b) relaciona, portanto, corporificação à universalidade e contexto à variação, como dois aspectos da pressão por coerência na conceptualização metafórica, aos quais os falantes estão submetidos ao organizarem conceptualmente seu pensamento usando metáforas. Dois tipos de contexto são postulados pelo autor: global e local. 0 primeiro reúne fatores contextuais que afetam toda uma comunidade linguística, quando algo é conceptualizado metaforicamente. $O$ segundo compreende fatores contextuais que afetam conceptualizadores particulares em situações específicas.

Entre os contextos globais, apontados por Kövecses (2010b), encontram-se os seguintes: (i) ambiente físico (geografia, fauna, flora); (ii) fatores sociais, como diferenças nas metáforas produzidas por homens e mulheres; (iii) contexto cultural, como conceitos e valores em foco que podem determinar domínios de experiência usados em metáforas; (iv) memória seletiva (differential memory), como fatos do passado que podem interferir na conceptualização de certas metáforas; (v) interesses e preocupações diversas presentes em toda a sociedade, que podem gerar metáforas acerca dos acontecimentos. Contextos globais e locais são vistos num continuum do local mais imediato ao global mais geral.

Em termos de contexto local, Kövecses (2010b) analisa o efeito do contexto físico imediato, como furacões e enchentes, que podem gerar metáforas em uma cidade. Outro contexto local, relacionado ao uso de metáforas, é o conhecimento das entidades participantes do discurso, que incluem 
o falante, o ouvinte (ambos conceptualizadores) e a entidade ou processo sobre o qual se fala (tópico, tipo de conhecimento ou informação expressa explícita ou implicitamente numa porção de discurso, segundo Kövecses). O contexto linguístico também é analisado como local. Como ressalta Kövecses (2010b), os contextos locais e globais podem afetar conjuntamente a conceptualização metafórica.

Os domínios fonte e alvo, ativados nas projeções metafóricas, compreendem conhecimentos armazenados na forma de modelos cognitivos idealizados ( $\mathrm{MCls}$ ): um conjunto coerente e estável de representações do conhecimento que pode ser organizado de várias maneiras (LAKOFF, 1987). Alguns dos $\mathrm{MCls}$ subjacentes às conceptualizações são fundamentados por esquemas imagéticos, que se formam por meio da percepção sensório-motora das experiências humanas mais primitivas, ligadas a uma série de situações experienciadas na interação com o ambiente (GIBBS; COLSTON, 2006[1995]). MCls e esquemas imagéticos tornam-se rotinas cognitivas, armazenadas na base de conhecimento, devido à natureza corporificada e enciclopédica da construção de sentidos.

Passa-se, em seguida, à análise das expressões metafóricas.

\section{Expressões metafóricas e metonímicas em conversas}

Um dos aspectos que caracteriza a configuração do Banco de Dados Interacionais (BDI) é o fato de que, em algumas interações, a gravação foi realizada sem conhecimento prévio dos participantes das conversas. Esse aspecto revelou uma tendência nesta amostra de fala, pois há um número um pouco maior de expressões metafóricas nas falas de quem não sabia previamente da gravação: 47 casos de conversas entre falantes sem conhecimento prévio da gravação contra 36.

Uma possível explicação para o número menor de metáforas em interações cujos falantes sabiam que estavam sendo gravados é 0 fato de 0 conhecimento prévio da gravação diminuir a espontaneidade da comunicação. Nesse caso, com base em Kövecses (2010b), pode-se postular que os falantes sofrem pressão pela coerência ligada ao contexto da conceptualização por saber da gravação em andamento, enquanto interagem com seus interlocutores. Apesar de as interações não apresentarem diferença na organização e nas UEs, em relação àquelas com mais expressões metafóricas, acredita-se que o contexto local de conceptualização seja influenciado por algum tipo cuidado por parte do falante, embora a quantidade de dados impeça uma generalização dessa forma de interpretar os números.

Os domínios fontes e alvos mais frequentes na conceptualização das expressões metafóricas do BDI figuram na literatura sobre metáforas/metonímias conceptuais, bem como a tendência de certos domínios figurarem predominantemente como alvo ou fonte. Conforme expresso na Tabela (1), OBJETO e ANIMAL são ativados majoritariamente como fonte, enquanto emoção e economia consistem em domínios alvos da projeção metafórica.

Tabela 1 - Índice de domínios alvo e fonte

\begin{tabular}{lcc}
\hline \multicolumn{1}{c}{ Domínio } & Alvo & Fonte \\
\hline PESSOA & 13 & 09 \\
EMOÇÃO & 14 & 01 \\
OBJETO & 01 & 13 \\
CORPO HUMANO & 05 & 08 \\
ECONOMIA & 11 & - \\
ANIMAL & - & 11 \\
\hline
\end{tabular}

Corroborando a assunção basilar de que a construção de sentidos é corporificada observou-se a ativação do domínio PESSOA como fonte e alvo. Os excertos (1) a (4) ilustram esse domínio.

(1) BDI 1
073 (Ana)
074
075 (Rom)
076
077
078 (Mar)
Quem pegou a salada nesse prato Nada. Deve tá caindo todo Fui pegar mais porque o prato tá= pequenininho. Tá vendo como o= 


$\begin{array}{ll}079 & \text { ambiente faz as pessoas. } \\ 080 \text { (Jur) } & \text { O PRATO faz as pessoas. } \\ 081(?) & \text { Hum= } \\ 082 & \text { Oi? } \\ 083 & \text { Ele falou pra mim que o ambiente faz } \\ & \text { as pessoas eu falei que o prato FAZ } \\ & \text { as pessoas } \\ 084 \text { (Nei) } & \text { Olha não tão deixando eu falar } \\ 085 & \text { Jurema dá cada= } \\ 086 & \text { coice inoportuno. ((Risos)) }\end{array}$

No excerto (1), que se passa num restaurante do campus da UFRJ no Fundão, há duas conceptualizações metafóricas: PESSOA É OBJETO e PESSOA É ANIMAL. No primeiro caso, a falante (Jur) baseia-se no contexto linguístico para tecer um comentário sobre o interlocutor que pegou mais comida, já que, neste local, a repetição de comida não seria cobrada. Pode-se considerar que a expressão metafórica começou a ser ativada na unidade anterior, quando a expressão popular, culturalmente conhecida pelos conceptualizadores, "o ambiente faz as pessoas" foi expressa.

A expressão criada, a partir do ditado, foi motivada metonimicamente, visto que o prato composto pela pessoa a quem se destina 0 comentário jocoso/irônico caracterizaria a atitude da pessoa de pegar mais comida sem custo. Esse caráter jocoso/irônico é reforçado pela pronúncia enfática da palavra prato, registrada em maiúsculas na transcrição.

$\mathrm{Na}$ sequência do excerto (1), o comentário jocoso/irônico de (Jur) levou-a a ser caracterizada como um animal que dá coice. Como ocorre no caso da UEs 085-086, o caráter jocoso permeia oito expressões metafóricas com ANIMAL como domínio fonte.

\section{(2) BDI 2A}

0511 (Jo)

Vamos puxar o carro? (BDI 2A)

\section{(3) BDI 6}

086 (Edw)

087

\section{Eu acho que o Rio sempre anda mais depressa}

\section{(4) BDI 2B}

131 (Mar)

132

135 (Sil)

136 (Mar) 137

\author{
Esse aqui olha \\ dourado. [...] \\ Esse tá bonito. \\ Mas esse aqui tá VIvo \\ tá um PÊssego
}

Na expressão metafórica do excerto (2), usada ao final de uma conversa entre estudantes no alojamento masculino da UFRJ, PESSOA é conceptualizada como MÁQUINA, devido à analogia entre o movimento de automóveis e o do corpo humano que usa veículos para locomoção. Logo, há, na construção puxar o carro com sentido de sair, uma base metonímica, já que o ato de dirigir um carro, meio usado para deslocamento propicia acesso mental ao ato de sair, a saber: INSTRUMENTO PELO ATO.

A conceptualização PESSOA É MÁQUINA baseiase numa metonímia, que, por sua vez, relaciona-se aos esquemas imagéticos de PERCURSO e PARTETODO, surgido da experiência física com coisas compostas de partes e deslocamentos. A construção de sentido ocorre num contexto cultural e linguístico, devido à ativação do conhecimento da expressão e à percepção de encerramento próximo da conversa, um conhecimento das instâncias de organização conversacional: papel dos participantes e tópico.

Diferenciando-se de (2), no excerto (3), o domínio PESSOA é fonte, na medida em que MUNICÍPIO é conceptualizado como PESSOA que caminha. $O$ trecho de (3), que ocorre numa reunião entre professora e alunas de uma turma do Mestrado em Educação da UFF, refere-se ao fato de, no Rio, as questões sobre alfabetização serem mais trabalhadas. Esse tipo de conceptualização é recorrente nos estudos sobre metáforas/metonímia. A essa concepção do Rio, subjaz o esquema imagético de PERCURSO.

O excerto (4) exprime um enunciado sobre um batom durante uma conversa entre universitárias acerca dos produtos da Natura vendidos por uma delas. Postulou-se, para tal UE, a conceptualização OBJETO É PESSOA. Embora se pudesse propor um domínio fonte como SER VIVO, optou-se por PESSOA, devido à corporificação de sentido, base acionada recorrentemente no pensamento analógico. Acreditase que a cor dourada, citada nas UEs 131-132, também pela falante (Mar), tenha sido um gatilho no contexto linguístico para a caracterização do batom 
como algo vivo. Esse sentido é reforçado pela analogia com pêssego na UE 137.

A mistura de sentidos físicos, como visão, paladar, olfato e tato, também está ligada ao caráter experiencialista do significado no âmbito da LC, que concebe uma relação entre os aspectos ligados à linguagem e outros componentes da cognição. No excerto (5), ocorre uma analogia entre olfato e paladar na caracterização de outro produto da Natura.

\begin{tabular}{|c|c|}
\hline (5) $\mathrm{BDI} 2 \mathrm{~B}$ & \\
\hline 196 (Sil) & Tem um sabonete ali \\
\hline $\begin{array}{l}197 \\
\text { mãe }\end{array}$ & compra pra dar de presente pra sua \\
\hline 198 (Ana) & Quanto é? \\
\hline 199 (Sil) & Vou comprar \\
\hline 200 & $\begin{array}{l}\text { eu comprei um a mais pra dar pra } \\
\text { minha mãe }\end{array}$ \\
\hline 201 & TÃO gosTO=so. \\
\hline
\end{tabular}

Essa associação, aparentemente simples, devido ao seu caráter físico e cotidiano, exprime uma conceptualização que envolve sensações sinestésicas causadas pelo sabonete: o perfume causa bem-estar que pode ser considerado um tipo de emoção, que, por sua vez, leva à associação entre perfume e sabor. Assim, a partir das sensações físicas desencadeadas pelo odor agradável do sabonete, pode-se postular a conceptualização de EMOÇÕES COMO SABOR, de base metonímica, na medida em que as alterações físicas causadas pelo olfato e paladar convertem-se em propriedades atribuídas ao sabonete.

A pronúncia enfática, representada por letras maiúsculas e alongamento (=), pode ser considerada evidência do entusiasmo quanto aos produtos manuseados pelas interlocutoras dessa etapa da conversa. O domínio alvo EMOÇÃo também aparece ligado à sensação física do paladar no trecho (6).

$\begin{array}{ll}\text { (6) BDI 1 } & \\ 026 \text { (Mar) } & \text { Neide } \\ 027 & \text { você está amarga } \\ 028 & \text { e cruel } \\ 029 & \text { perversa } \\ 030 & \text { abominável. ((Risos)) } \\ 031 \text { (Jur) } & \text { Todo petista é assim }\end{array}$

No início da conversa, ambientada num restaurante da UFRJ, graduandos discutem os resultados do primeiro turno da eleição presidencial de 1989, disputada por Collor, Lula e Brizola. Após comentar uma charge de lque sobre o desempenho dos candidatos, o falante (Mar) rebate um comentário de Neide, inaudível na gravação, com a passagem (6), chamando-a de "amarga".

De acordo com uma crença antiga, o mau humor poderia levar o baço a produzir "bile negra", causando um amargor na boca, que pode representar a emoção negativa, em termos metonímicos, como EFEITO PELA CAUSA. Essa compreensão estendeu-se à pessoa acometida por tal emoção, caracterizando-a metaforicamente pelo efeito gerado pela emoção. Assim, tal conceptualização de emoção pode ser fundamentada pela metáfora de base metonímica EMOÇÃO É SABOR.

Os adjetivos cruel, perversa e abominável, seguidos de risos ao final do turno de (Mar) e da UE 031 da falante (Jur), levaram à postulação de um caráter jocoso/irônico para o contexto de produção da expressão metafórica. Além do contexto linguístico, o trecho envolve o evento das eleições, que pode ser considerado global, porque se trata de um acontecimento político de âmbito nacional. A quantidade de votos insuficiente de Lula contextualiza o comentário sobre o mau humor dos petistas.

Confirmando outros estudos, o domínio da EMOÇÃO costuma ser alvo nas conceptualizações metafóricas, porém, nos dados analisados, encontrou-se uma ocorrência de expressão linguística metafórica a que se pode atribuir tal domínio como fonte da projeção/analogia. Durante uma conversa no trailer do alojamento da UFRJ, uma das participantes pergunta se sua interlocutora lhe venderia uma fatia de calabresa; em seguida, outra conceptualizadora faz a seguinte pergunta: Iva cê tá numa pobreza tão dramática assim? (BDI 4-229). O adjetivo dramática evidencia a conceptualização metafórica de pobreza em termos dos efeitos emocionais causados pelas dificuldades orçamentárias.

O domínio da ECONOMIA, categorização que engloba passagens sobre situação financeira pessoal e institucional, como dinheiro, orçamento, preços, 
inflação, foi alvo em 11 expressões metafóricas, entre as quais as dos excertos (7) e (8).

\section{(7) BDI 9D $030(\mathrm{~F} 1)$}

031

032

033

(8) BDI 9D

$270(\mathrm{~F} 1)$

271

272

273

274

275

276

277

278

279

(9) BDI 10

121 (Sen)

122

123

124 (Mar)

125 (Sen)
Onde a gente já ouviu falar que algum empresário perdeu um centavo com o Plano Collor Nenhum!

Só o dinheiro da classe média tá depositado na caderneta de poupança é que tá congelado até hoje.

A troco de que raciocínio a gente vai aceitar o nosso salário seja reduzido à metade?

A troco de quê?

Qual é o critério?

Qual é o sacrifício?

que//

que o sacrifício que essas empresas estão fazendo

para degolar a inflação?

\section{Sujeito à alteração este mês ou para o mês que vem outubro? \\ Só para outubro. \\ Você já está dando o preço já na boca do fim do mês}

Não por acaso, o domínio alvo ECONOMIA aparece em contextos de conceptualização que evocam tópicos sobre questões financeiras: o discurso de sindicalistas em frente à sede da Petrobras (excertos 7 e 8) e diálogo entre uma funcionária de uma agência de viagem e uma cliente em busca de informações sobre diárias de hotel e pacotes turísticos (9). Em (7), DINHEIRO é conceptualizado como SUBSTÂNCIA que sofre congelamento, expressando a imobilidade financeira do assalariado.

Em (8), INFLAÇÃO é conceptualizada como PESSOA a ser degolada. A postulação de PESSOA como domínio fonte e não ANIMAL, por exemplo, devese ao fato de tal forma verbal relacionar-se ao pescoço, parte do corpo humano que nem todos os animais apresentam. Além disso, culturalmente, separar o pescoço da cabeça consiste em um ato violento usado entre pessoas ao longo da história da humanidade.
O excerto (9) refere-se a informações sobre preços que, em 1990, mudavam com frequência devido à inflação, por isso a preocupação da cliente (Sen) de saber a validade do valor fornecido por (Mar), funcionária da agência de viagem. A expressão boca do fim do mês conceptualiza a MOVIMENTAÇÃO ECONÔMICA como uma espécie de CORPO que vai ingerindo os preços. Em razão de a boca ser o primeiro órgão movimentado para a ingestão de alimentos/substâncias, pode ter sido usada para conceptualizar início de eventos em termos metafóricos, metonimicamente motivados, como o limiar do fim do mês.

O domínio CORPO HUMANO, assim como PESSOA, aparece como fonte e alvo. Diferenciando-se de (9), no trecho (10), coRPo aparece como domínio alvo conceptualizado como MÁQUINA.

(10) BDI 10

309 (Sen)

310

311

312

313

314

315

Agora eu vou ao médico.
Ver se a minha caveira
está com as
molas JUN=tas
juntas
até da mão=
do pé

Após obter as informações desejadas com a funcionária da agência de viagem, a falante (Sen) comenta que vai ao médico, justificando o motivo da consulta. Para tal, refere-se ao próprio corpo metonímica e metaforicamente como caveira. A base metonímica relaciona-se ao fato de que os ossos são uma parte do corpo humano, os quais, em conjunto, categorizam metaforicamente o conceito de CAVEIRA, uma entidade constituída apenas por ossos.

$\mathrm{Na}$ sequência, emprega a expressão molas JUN=tas para conceptualizar o funcionamento das articulações do corpo por meio de um mecanismo típico de máquinas. Logo, pode-se propor a metáfora CAVEIRA HUMANA É MÁQUINA como uma especificação de base metonímica da metáfora CORPO É MÁQUINA para o trecho (10).

Assim como CORPO, o domínio OBJETO figurou predominantemente como fonte, todavia no enunciado do excerto (4), "Mas esse aqui tá VIvo" (BDI 2B-136), em que a falante se refere a um batom, 
ocorre um caso de personificação OBJETO É PESSOA. No excerto (11), ilustra-se mais um caso de OBJETO como domínio fonte.

(11) BDI 1

424 (Ana)

425

426 (Nei)

427 (Ana)

428

429 (Jur)

430

431

432

433

434

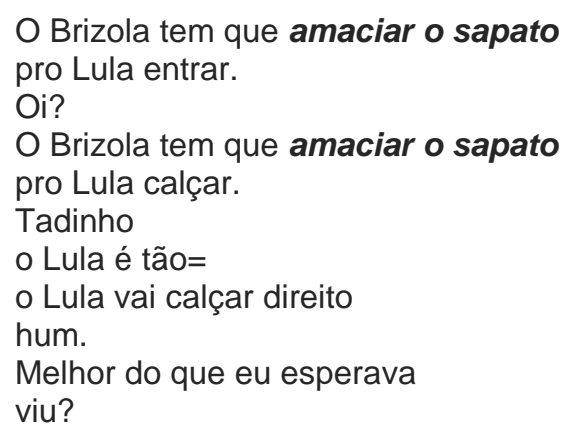

Na passagem de (11), o papel dos candidatos nas eleições de 1989, tópico de uma conversa que ocorre num restaurante da UFRJ (Fundão), é conceptualizado como um objeto de vestuário. Nesse caso, interpretou-se sapato como uma referência à campanha presidencial, na qual Brizola, depois da perda no primeiro turno, apoiaria o candidato Lula no segundo. A comparação entre os papéis de Brizola e Lula vinha sendo discutida em termos de quem seria mais experiente, querido pela população ou temido pelos políticos no poder e pela classe dominante. Após um comentário da falante (Nei), quanto à expectativa positiva em relação a Lula na presidência, a falante (Ana) expressa, no excerto (11), o referido comentário sobre o papel de Brizola como aliado de Lula no segundo turno.

A ativação de SAPATO propicia uma relação com CORPO, visto que sapato cobre uma parte do corpo humano, protegendo-o durante o caminhar. Portanto, ao afirmar que Brizola teria de amaciar o sapato para Lula, o falante estaria defendendo a importância do apoio de Brizola no caminho político de Lula nas eleições de 1989. Logo, a aparente simplicidade da afirmação revela esquemas de conhecimentos basilares, como esquemas imagéticos de PERCURSO e CONTÊINER, na medida em que o corpo pode ser compreendido como um contêiner que percorre um caminho.

Esses esquemas fundamentam conceptualizações metafóricas de base metonímica, visto que ALIANÇAS POLÍTICAS são compreendidas como AMACIAMENTO DE SAPATO pode ser considerada uma espécie de desdobramento de uma metáfora mais abrangente: SISTEMA POLíTICO É OBJETO (COMPARTILHADO). A base metonímica corpórea consiste na seleção de um objeto usado para representar o apoio à base da candidatura de Lula. Além do contexto linguístico imediato, que envolve a discussão anterior sobre as eleições; o contexto global das eleições e o conhecimento das entidades participantes da interação, papéis de Brizola e Lula na política nacional e conceptualizadores, compõem o cenário de construção de sentido desse excerto.

\section{Considerações finais}

Espera-se que, por meio dos resultados preliminares resumidos aqui, tenha-se mostrado a relevância do estudo das metáforas/metonímias conceptuais. Embora não se possa controlar (ou motivar) a produção de metáforas em eventos reais de uso da língua, as expressões metafóricas encontradas corroboram o papel do pensamento metafórico na construção de sentidos.

Comprovaram-se achados da literatura quanto aos domínios mais recorrentes, mesmo em uma amostra reduzida de expressões, conforme as categorizações elencadas por KÖVECSES (2010a): entre os domínios alvos mais recorrentes encontramse (i) ESTADOS E EVENTOS PSICOLÓGICOS E MENTAIS desejo, moralidade, pensamento; (ii) GRUPOS E PROCESSOS SOCIAIS - sociedade, política, economia, relacionamentos humanos, comunicação; (iii) EXPERIÊNCIAS PESSOAIS E EVENTOS - tempo, vida, morte. Entre os domínios fonte mais comuns encontram-se (i) CORPO HUMANO; (ii) SAÚDE E DOENÇA; (iii) ANIMAIS; (iv) PLANTAS; (v) PRÉDIOS E CONSTRUÇÕES; (vi) MÁQUINAS E FERRAMENTAS; (vii) JOGOS E ESPORTES.

Em razão da extensão deste texto, não se pode ilustrar todos os tipos de domínio encontrados, incluindo aqueles com frequências menores, porém foi possível comprovar o elenco de domínios citados em outros estudos. Algumas conceptualizações ainda precisam de refinamento em termos da subjacência de metáforas conceptuais e de esquemas imagéticos. 
Contudo, apesar da aparente simplicidade, em termos estruturais e semântico-pragmáticos, do raciocínio ativado em algumas passagens das conversas, acredita-se que alguns casos não se explicam completamente por meio da projeção metafórica unidirecional entre dois domínios. Casos de conceptualização metafórica de base metonímica, por exemplo, seriam descritos adequadamente em termos de compressão das projeções seletivas de elementos ativados por mais de dois domínios ou espaços mentais, ou seja, por meio de mesclagens conceptuais, uma das tarefas em andamento no estágio atual da pesquisa.

Comprovou-se também a importância do contexto em que ocorrem as conceptualizações das expressões metafóricas, porque motivam suas ocorrências. Nota-se, assim, que devido à dinamicidade e à complexidade, que envolvem as organizações conceptuais de conversas informais, as expressões metafóricas representaram o entrelaçamento da ativação de elementos contextuais, sociais, enciclopédicos, linguísticos e interacionais.

\section{Referências}

CHAFE, Wallace. Cognitive constraints on information flow. In: TOMLIN, R. Coherence and grounding in discourse. Amsterdam/Philadelphia: John Benjamins, 1987.

Linking intonation units in spoken English. In: HAIMAN, J. \& THOMPSON, S. (eds.). Clause combining in grammar and dicourse. Amsterdam/Philadelphia: John Benjamins, 1988. p. 1-27.

DU BOIS, J. et alii (eds.). Discourse transcription. Santa Barbara Papers in Linguistics vol. 4. Santa Barbara: University of California, 1992.

EVANS, Vyvyan; GREEN, Melanie. Cognitive linguistics: an introduction. Edinburgh: Edinburgh University Press, 2006.

GIBBS Jr., Raymond W.; COLSTON, Herbert L.. The cognitive psychological reality of image schemas and their transformations. In: GEERAERTS, Dirk (ed.). Cognitive linguistic: basic readings. Berlin/New York: Mouton de Gruyter, 2006.

KÖVECSES, Zóltan. Metaphor and in culture: universality and variation. Cambridge: Cambridge University Press, 2005.

Metaphor: a practical introdution (2nd ed.). New York: Oxford University Press, 2010a[2002].

A new look at metaphorical creativity in cognitive linguistics. Cognitive Linguistics 214, 2010, p. 663-697.

LAKOFF, George. Women, fire and dangerous things. Chicago: University of Chicago Press, 1987.

LAKOFF, George; JOHNSON, Mark. Metáforas da vida cotidiana [coordenação de tradução Mara Sophia Zanotto]. Campinas-SP: Mercado de Letras; São Paulo: EDUC, [1980] 2002.

LANGACKER, Ronald W.. Cognitive grammar: a basic introduction. New York: Oxford University Press, 2008

RONCARATI, Cláudia (org.). Banco de dados interacionais. Rio de Janeiro: Faculdade de Letras - UFRJ/CNPq, 1996. 